\title{
Risk Factors Associated with Methotrexate Intolerance in Rheumatoid Arthritis Patients
}

This article was published in the following Dove Press journal:

Open Access Rheumatology: Research and Reviews

\author{
Haya Almalag (D) \\ Hanan H Abouzaid (D) \\ Lamya Alnaim (D) \\ Jawza Albaqami ${ }^{\prime}$ \\ Rawan Al Shalhoub' \\ Ibrahim Almaghlouth ${ }^{2,3}$ \\ Maha Dessougi ${ }^{4}$ \\ Amal Al Harthi $\mathbb{D}^{4}$ \\ Mohamed Bedaiwi ${ }^{2}$ \\ Eman Alfi ${ }^{5}$ \\ Mohammed A Omair $\mathbb{D}^{2}$ \\ 'Department of Clinical Pharmacy, \\ College of Pharmacy, King Saud \\ University, Riyadh, Saudi Arabia; \\ ${ }^{2}$ Rheumatology Unit, Department of \\ Medicine, King Saud University Medical \\ City, Riyadh, Saudi Arabia; ${ }^{3}$ College of \\ Medicine Research Centre, King Saud \\ University, Riyadh, Saudi Arabia; \\ ${ }^{4}$ Rheumatology Department, Security \\ Force Hospital, Riyadh, Saudi Arabia; \\ ${ }^{5}$ Clinical Pharmacy Department, \\ Pharmaceutical Services, King Saud \\ University Medical City, Riyadh, Saudi \\ Arabia
}

Background: Methotrexate (MTX) Intolerance Severity Score (MISS) has been previously validated in the Arabic language and has helped to detect high levels of intolerance in rheumatoid arthritis (RA) patients. The aim of the current study was to evaluate patient and disease characteristics associated with a high risk of MTX intolerance.

Materials and Methods: A cross-sectional interview-based survey was conducted using adult RA patients as a study group, who were visiting a specialized rheumatology clinic at King Saud University Medical City. The Arabic MISS was used in this survey. Statistical analyses were performed to understand associations between MTX-intolerant and MTXtolerant patients.

Results: A total of 117 patients were involved in this study. Of those, 101 (86.3\%) were females with a mean (SD) disease duration of 6.6 (5.7) years. The median (interquartile range (IQR)) Disease Activity Score-28 (DAS28) was 3.6 (3.6-4.1). MTX intolerance was observed in $55(47 \%)$ patients. The most predominant component in patients with a positive test was the behavioral component. Intolerant patients had a higher median of pain (47.3 vs. $50.0 ; \mathrm{P}=0.010)$ and patient global assessment (50.0 vs. 60.0; $\mathrm{P}=0.004)$ scales compared to those in tolerant patients. Additionally, MTX intolerance was associated with the female gender (adjusted odds ratio (AOR) 6.724; 95\% CI 1.420, 31.843, P =0.016), marital status (AOR 2.549; 95\% CI 1.037, 6.270, $\mathrm{P}=0.042$ ) and DAS28 (AOR 1.612; 95\% CI 1.032, $2.517, \mathrm{P}=0.036)$. There was no significant difference between the two groups in the remaining disease activity parameters, background therapies, seropositivity, and smoking status $(\mathrm{P}>0.05)$.

Conclusion: Patient characteristics, rather than disease activity, significantly impact MTX intolerance. Behavioral component is the main driver of intolerance. Intolerant patients have higher patient-reported outcomes. Qualitative studies are needed to explore causes and potential solutions to MTX intolerance.

Keywords: methotrexate, rheumatoid arthritis, intolerance

\section{Introduction}

Methotrexate (MTX) is a gold standard medication for management of rheumatoid arthritis (RA). ${ }^{1}$ It has been classified as one of the most important traditional disease-modifying antirheumatic drugs (DMARDs). ${ }^{2}$ MTX is an anti-folate that inhibits DNA synthesis of some inflammatory cells, thus exhibit an immunomodulatory action. Although it is considered one of the most commonly used DMARDs, it is known to have certain disadvantages and side effects that can limit its use. ${ }^{3}$ MTX side effects range from mild gastrointestinal (GI) tract symptoms to lifethreatening pneumonitis. ${ }^{3}$ It is essential to recognize these symptoms as they can negatively impact a patient's quality of life and hinder their adherence to MTX
Correspondence: Haya Almalag Department of Clinical Pharmacy College of Pharmacy, King Saud University, Riyadh III49, Saudi Arabia Tel +966 II 18057859

Email halmalaq@ksu.edu.sa 
therapy. ${ }^{4}$ Some of the most frequently encountered side effects of MTX administration are GI adverse effects, which can be minimized by treatment with folic acid. Moreover, anticipatory and associative symptoms, like behavioral symptoms, are also encountered with MTX use. The mechanism behind MTX related GI intolerance can be attributed to two processes; a) the gastrointestinal epithelium is sensitive to MTX regardless of the folate deficiency, and as time progresses it becomes further sensitized as a result of MTX accumulation, b) the second mechanism behind this intolerance may be through simulation of chemotactic trigger zone., ${ }^{5,6}$ Due to the wide spectrum of MTX intolerance symptoms, a valid measurement tool is essential to identify patients with intolerance. One of the most used tools to enable such identification is the MTX Intolerance Severity Score (MISS) questionnaire. This questionnaire was constructed and validated to be used in juvenile idiopathic arthritis patients, and later in patients of other rheumatic diseases, including RA and psoriatic arthritis. Using MISS, MTX intolerance was considered prevalent if the interview score was six or higher, along with a score $\geq 1$ for anticipatory, associative and/or behavioral components. ${ }^{7,8}$ Furthermore, the MISS questionnaire was translated and validated in multiple languages, one of which is Arabic, the language used in this study. ${ }^{9}$ MTX intolerance and its relation to multiple RA related factors have not been thoroughly described in the literature. Therefore, through this study, we aimed to determine the prevalence of MTX intolerance in a Saudi population, and assess its relation to multiple RA related factors.

\section{Materials and Methods}

\section{Study Design, Settings, and Participants}

The study focused on interview-based cross-sectional survey of adult patients (age $\geq 18$ years) with RA classified according to European League Against Rheumatism and American College of Rheumatology 2010 classification criteria. ${ }^{10}$ Patients were recruited from rheumatology clinics at King Saud University and Medical City at Riyadh, Saudi Arabia. Participants in the cross-sectional survey were enrolled after obtaining informed consent, which was approved by a local institutional review board and was in accordance with the Declaration of Helsinki. To be included in the study, the patient had to be cognitively stable, on MTX therapy for at least 3 months. Those patients with gastrointestinal cancer, mental challenges, children, and adolescents were excluded. The study was observational in nature and was guided by Strengthen the Reporting of Observational Studies in Epidemiology checklist. $^{11}$

\section{Variables, Data Source and Measurements}

A data collection sheet was designed to gather information on patients from two sources. The first source was an interview-based assessment of the MTX intolerance score through a translated and validated MISS. The questionnaire contained 12 questions that were divided into four domains, abdominal pain, nausea, vomiting, and behavioral symptoms. The amplitude of each domain was ranked from 0 to 3 as, no complaint ( 0 point), mild (1 point), moderate ( 2 points), and severe ( 3 points). ${ }^{9}$ The numbers were then totaled and if the patient had a score of 6 points or greater, with $\geq 1$ point for anticipatory, associative and/or behavioral items, then the patient was considered MTX-intolerant. In the interviews, patients were also asked about MTX specific information, such as folic acid dosage, time of administration in relation to MTX, time of MTX in relation to meals, route of MTX, and time for MTX administration (morning or evening). A second source of data was obtained from patient files, during their clinical visits. RA patients were subdivided into seropositive and seronegative, according to the presence versus absence of anti-cyclic citrullinated peptide (antiCCP) and of rheumatoid factor (RF), where the presence of either or both of these types of autoantibody defined the seropositive subset of disease. ${ }^{12}$ In addition, data on multiple RA activity-related scores were obtained as the follows: 1) pain reported by a patient using $100 \mathrm{~mm}$ visual analogue scale; 2) swollen joint count (SJC), assessed by an attending physician, confirmed by ultrasound, and ranged from 0 to $28 ; 3$ ) tender joint count (TJC), which was also assessed by the attending physician and ranged from $0-28$; 4) patient global assessment of disease activity (PtGA), which is a self-assessment of the overall disease activity using a $100 \mathrm{~mm}$ visual analogue scale, where a proposed definition of low disease activity was $\leq 20.0$ (scale $0-100 \mathrm{~mm}$ ); 5) provider global assessment of disease activity (PrGA), which is a clinical assessment of overall disease activity performed by the attending physician using a $100 \mathrm{~mm}$ visual analogue scale where the scale ranged from 0 to 100 , and where a proposed definition of low disease activity was $\leq 15.0$; 6) disease activity score with 28-joint counts (DAS28) combines a 28SJC, 28TJC, erythrocyte 
sedimentation rate (ESR), and PtGA into an overall measure of RA disease activity; 7) a simplified disease activity index (SDAI) that included 28SJC, 28TJC, PtGA, PrGA, and C-reactive protein (CRP); and 8) clinical disease activity index (CDAI) that combined 28SJC, 28TJC, PtGA, and PrGA into a single measure of RA disease activity. ${ }^{13}$ Other information related to patients that were not available in the data were obtained from patient files, including age, medical history, duration of RA, current medical therapy, dose, frequency, and laboratory results (erythrocyte sedimentation rate and rheumatoid factor). All data obtained at the time of interview visits were labeled as index visits. The recruitment was done between June and November 2017.

\section{Statistical Analysis}

Data was coded and entered in Statistical Package for Social Science software (version 25 SPSS $^{\circledR} 25$ ) and Microsoft office Excel 365. Data entry check was carried out by re-entering $10 \%$ of the data for error rate calculation. Results were reported as numbers and percentages for categorical variables. Mean and standard deviation were presented for continuous and normally distributed data, and as median and interquartile range (IQR) for nonnormally distributed data. Patients were classified as "MTX-intolerant" if they had a MISS score of more than 6 along with a score $\geq 1$ for anticipatory, associative and/or behavioral components, and as "MTX-intolerant" if they did not meet the previous criteria Variables of the two groups, MTX-tolerant and MTX-intolerant, were compared using $t$-test for normally distributed data, and Mann Whitney $U$-test for non-normally distributed data. Pearson correlation coefficient was calculated between two continuous variables in which at least one followed a normal distribution. Categorical variables were compared between the two groups by a chi-square test. Bivariate logistic regression was performed to predict factors related to MTX intolerance after adjusting for confounding variables like age, gender, and disease duration, regardless of their significance. A radar chart of MISS and anticipatory, associative, and behavioral components was prepared using Microsoft office Excel 365. For missing values, imputation was used by replace them with series mean after checking that the missing values occurred at random. Multiple linear regression was used to predict changes in MISS score as a dependent variable and disease activity scores (DAS28 ESR, CDAI, and SDAI) as independent variables taking confounding variables age, gender, and disease duration into consideration.

\section{Results}

A total of 117 patients were included in the study as all patients who were approached agreed to participate, and according to their MTX intolerance scores, 62 patients were classified as MTX-tolerant, while 55 patients were MTX-intolerant. Majority of the participants were women, with a significantly higher percentage of females in the MTX-intolerant group, $\mathrm{n}=52(94.5 \%)$, compared to the MTX-tolerant group, $\mathrm{n}=49(79.0 \%)$, at $\mathrm{P}=0.015$. The mean $( \pm \mathrm{SD})$ age of the patients in the MTX-tolerant group, $52.9( \pm 13.7)$, was comparable with that of the MTXintolerant group, $48.5( \pm 11.2)$, at $\mathrm{P}=0.257$. More nonsmokers, $\mathrm{n}=58(93.5 \%)$, were in the MTX-tolerant group compared to that in the MTX-intolerant group, $\mathrm{n}=54$ (98.2\%), at $\mathrm{P}=0.369$. Table 1 represents the demographical data and a bivariate analysis of the difference in baseline demographics between MTX-tolerant and MTX-intolerant groups. Information on marital status, place of residence, level of education, and whether patients are receiving other medications or not are given in Table 1.

Information related to MTX is available in Table 2. Participants received a comparable MTX dosage, with a mean of $15.0( \pm 3.8)$ milligram/week in MTX-tolerant group and $15.5( \pm 3.9)$ milligram/week in the intolerant group, at $\mathrm{P}=0.525$. Oral route was the dominant route of administration in both groups, i.e., $\mathrm{n}=45(72.6 \%)$ in MTX-tolerant and $\mathrm{n}=44(80.0 \%)$, in MTX-intolerant group. The second most dominant route of administration was through subcutaneous injections with $\mathrm{n}=17(27.4 \%)$ in the MTX-tolerant and $n=11(20.0 \%)$ in the MTXintolerant group, at $\mathrm{P}=0.348$. Information on MTX in relation to meal is also shown in Table 2.

RA related information is detailed in Table 3. Participants of both groups had comparable RA duration and anti- CCP results. MTX-intolerant group had a significantly higher MISS score with a mean of 10.9 ( \pm 4.6 ), compared to that of MTX-tolerant group which was $2.2( \pm 1.8)$, at $\mathrm{P} \leq 0.001$, even after adjusting for confounding variables like age, gender, and disease duration. Higher number of participants had positive RF in MTX-tolerant, $\mathrm{n}=59(95.2 \%)$, compared to that in MTX-intolerant group, $\mathrm{n}=50(90.0 \%)$, at $\mathrm{P}=0.472$. Pain score using 100 visual analogue scales was higher in the MTX-intolerant group (50, IQR 50.0-70.0)) than that in MTX-tolerant group (47.3, IQR 47.3-50.0), and 
Table I Baseline Demographic Information of Participants and Bivariate Analysis of Difference Between Methotrexate Tolerant and Methotrexate Intolerant Groups

\begin{tabular}{|c|c|c|c|c|}
\hline \multirow{2}{*}{$\begin{array}{l}\text { Baseline } \\
\text { Characteristic }\end{array}$} & Total & Tolerant & Intolerant & \multirow[t]{2}{*}{$P$-value } \\
\hline & $(n=117)$ & $(n=62)$ & $(n=55)$ & \\
\hline Age, mean (SD) & $50.8(12.7)$ & $52.9(13.7)$ & $48.5(11.2)$ & 0.257 \\
\hline $\begin{array}{l}\text { Gender, n (\%) } \\
\text { Female }\end{array}$ & I0I (86.3) & $49(79.0)$ & $52(94.5)$ & $0.015^{*}$ \\
\hline $\begin{array}{l}\text { Marital status, } \\
\text { n (\%) } \\
\text { Unmarried } \\
\text { Married }\end{array}$ & $\begin{array}{l}32(27.4) \\
85(72.6)\end{array}$ & $\begin{array}{l}20(32.3) \\
42(67.7)\end{array}$ & $\begin{array}{l}12(21.8) \\
43(78.2)\end{array}$ & 0.206 \\
\hline $\begin{array}{l}\text { Living, n (\%) } \\
\text { In Riyadh }\end{array}$ & $95(81.2)$ & 48 (77.4) & 47 (85.5) & 0.267 \\
\hline $\begin{array}{l}\text { Education, n (\%) } \\
\text { Higher level of } \\
\text { education } \\
\text { Lower level of } \\
\text { education }\end{array}$ & $\begin{array}{l}30(25.6) \\
87(74.4)\end{array}$ & $\begin{array}{l}16(25.8) \\
46(74.2)\end{array}$ & $\begin{array}{l}14(25.5) \\
4 \mid(74.5)\end{array}$ & 0.965 \\
\hline $\begin{array}{l}\text { Smoking, n (\%) } \\
\text { Non-smoker }\end{array}$ & 112 (95.7) & $58(93.5)$ & $54(98.2)$ & 0.369 \\
\hline $\begin{array}{l}\text { Other } \\
\text { medications, n (\%) } \\
\text { No } \\
\text { Yes }\end{array}$ & $\begin{array}{l}14(12.0) \\
103(88.0)\end{array}$ & $\begin{array}{l}5(8.1) \\
57(91.9)\end{array}$ & $\begin{array}{l}9(16.4) \\
46(83.6)\end{array}$ & 0.254 \\
\hline
\end{tabular}

Note: *Significant according to a significance level of $P \leq 0.05$.

Abbreviation: SD, standard deviation.

this was statistically significant at $\mathrm{P}=0.010$. PtGA was also significantly higher in MTX-intolerant group with a median of 60.0 (IQR 59.1-80.0) compared to that in the MTX-tolerant group with a median of 50.0 (IQR 50.0-59.1), at $\mathrm{P}=0.004$. PrGA was comparable between the 2 groups, with similar median but different interquartile ranges of 48.0 (IQR 48.0-100.0) in the MTXtolerant group compared to 48.0 (IQR 48.0-80.0) in that of the intolerant group, $\mathrm{P}=0.934$. CRP was higher in the MTX-intolerant group compared to that in the MTXtolerant group at $34.2( \pm 128.7)$ and $20.0( \pm 13.6)$, respectively, and this was statistically insignificant at $\mathrm{P}=$ 0.390. Further details including information on ESR, folic acid dose, traditional DMARDs, and biologics are outlined in Table 3.

Furthermore, factors that are suspected to be associated with MTX intolerance among the study population were assessed using binary logistic regression adjusted for age, gender, and disease duration, as displayed in Table 4. Among these factors, females showed
Table 2 Baseline Methotrexate Related Information of Participants and Bivariate Analysis of Difference Between Methotrexate Tolerant and Methotrexate Intolerant Groups

\begin{tabular}{|c|c|c|c|c|}
\hline \multirow{2}{*}{$\begin{array}{l}\text { Baseline } \\
\text { Characteristic }\end{array}$} & Total & Tolerant & Intolerant & \multirow[t]{2}{*}{$P$-value } \\
\hline & $(n=1 \mid 7)$ & $(n=62)$ & $(n=55)$ & \\
\hline $\begin{array}{l}\text { Methotrexate } \\
\text { dose (milligram/ } \\
\text { week), mean } \\
\text { (SD) }\end{array}$ & $15.2(3.82)$ & I5.0 (3.8) & 15.5 (3.9) & 0.525 \\
\hline \multicolumn{5}{|l|}{$\begin{array}{l}\text { Route of } \\
\text { administration, } \\
\text { n (\%) }\end{array}$} \\
\hline Oral & $89(76.1)$ & $45(72.6)$ & $44(80.0)$ & 0.348 \\
\hline Subcutaneous & $28(23.9)$ & $17(27.4)$ & II (20.0) & \\
\hline \multicolumn{5}{|l|}{$\begin{array}{l}\text { Time of } \\
\text { administration, } \\
\text { n (\%) }\end{array}$} \\
\hline Morning & $32(27.4)$ & $18(29.0)$ & $14(25.5)$ & 0.665 \\
\hline Evening & $85(72.6)$ & $44(7 \mid .0)$ & $4 \mid(74.5)$ & \\
\hline \multicolumn{5}{|l|}{$\begin{array}{l}\text { Methotrexate in } \\
\text { relation to } \\
\text { meals, } n(\%)\end{array}$} \\
\hline Before & $6(5.1)$ & $3(4.8)$ & $3(5.5)$ & 0.851 \\
\hline Between & $17(14.5)$ & $8(12.9)$ & $9(16.4)$ & \\
\hline After & $94(80.3)$ & $5 I(82.3)$ & $43(78.2)$ & \\
\hline
\end{tabular}

Abbreviation: SD, standard deviation.

a significant association with higher MTX intolerance compared to that in males (adjusted odds ratio (AOR) 6.724 [95\% CI: 1.420, 31.843]; $\mathrm{P}=0.016$ ). Marriage was also significantly associated with a higher MTX intolerance (AOR 2.549 [95\% CI: 1.037, 6.270]; P = 0.042). MTX dosage did not show a statistical association with intolerance (AOR 1.041 [95\% CI: 0.942, 1.152]; $P=0.430$ ). MTX intolerance was not significantly associated with neither traditional DMARDs nor biologic with AOR 0.695 (95\% CI: 0.299, 1.615), $\mathrm{P}=$ 0.398 and AOR 1.640 (95\% CI: 0.707, 3.805), $\mathrm{P}=$ 0.250 , respectively. Similarly, the use of other medications was not statistically associated with MTX intolerance (AOR 0.548 [95\% CI: 0.163, 1.835]; $\mathrm{P}=0.329$ ). Moreover, DAS28 showed a significant association with higher MTX intolerance (AOR 1.612 [95\% CI: 1.032, 2.517]; $P=0.036$ ). PtGA also showed a significant association with higher MTX intolerance (AOR 1.023 [95\% CI: $1.007,1.040] ; \mathrm{P}=0.005$ ). On the other hand, PrGA did not show a statistical association with MTX intolerance (AOR 0.998 [95\% CI: 0.983, 1.013]; P = 
Table 3 Rheumatoid Arthritis Related Information of Participants and Bivariate Analysis of Difference Between Methotrexate Tolerant and Methotrexate Intolerant Groups

\begin{tabular}{|c|c|c|c|c|}
\hline \multirow[t]{2}{*}{ Baseline Characteristic } & \multirow{2}{*}{$\begin{array}{l}\text { Total } \\
(n=|| 7)\end{array}$} & \multirow{2}{*}{$\begin{array}{l}\text { Tolerant } \\
(n=62)\end{array}$} & \multirow{2}{*}{$\begin{array}{l}\text { Intolerant } \\
(n=55)\end{array}$} & \multirow[t]{2}{*}{$P$-value } \\
\hline & & & & \\
\hline Methotrexate Intolerance Severity Score (MISS), mean (SD) & $6.3(5.5)$ & $2.2(1.8)$ & $10.9(4.6)$ & $<0.001 *$ \\
\hline Rheumatoid arthritis duration, mean (SD) & $6.6(5.7)$ & $6.5(5.8)$ & $6.8(5.6)$ & 0.736 \\
\hline \multicolumn{5}{|l|}{ Rheumatoid factor (International Unit/milliliters), n (\%) } \\
\hline Negative & $8(6.8)$ & $3(4.8)$ & $5(9.1)$ & 0.472 \\
\hline Positive & $109(93.2)$ & $59(95.2)$ & $50(90.0)$ & \\
\hline \multicolumn{5}{|l|}{ Anti-cyclic citrullinated peptide (unit/milliliter), n (\%) } \\
\hline Negative & $2(1.7)$ & $\mathrm{I}(\mathrm{l} .6)$ & $\mathrm{I}(\mathrm{l} .8)$ & 1.000 \\
\hline Positive & $115(98.3)$ & $61(98.4)$ & $54(98.2)$ & \\
\hline \multicolumn{5}{|l|}{ Seropositive/Seronegative, n (\%) } \\
\hline Seropositive & $116(99.1)$ & $62(100.0)$ & $54(98.2)$ & 0.470 \\
\hline Seronegative & $\mathrm{I}(0.9)$ & $0(0)$ & $\mathrm{I}(\mathrm{I} .8)$ & \\
\hline Pain using 100 visual analogue scale, median (IQR) & $50.0(50.0-70.0)$ & $47.3(47.3-50.0)$ & $50.0(50.0-70.0)$ & $0.010 *$ \\
\hline Patient global assessment, median (IQR) & $59.1(59.1-70.0)$ & $50.0(50.0-59.1)$ & $60.0(59.1-80.0)$ & $0.004^{*}$ \\
\hline Provider global assessment, median (IQR) & $48.0(48.0-100.0)$ & $48.0(48.0-100.0)$ & $48.0(48.0-80.0)$ & 0.934 \\
\hline Erythrocyte sedimentation rate (millimeter/hour), mean (SD) & $23.0(16.5)$ & $22.4(\mid 3.7)$ & $23.7(19.3)$ & 0.663 \\
\hline C-reactive protein (milligram/Liter), mean (SD) & $26.7(88.7)$ & $20.0(13.6)$ & $34.2(128.7)$ & 0.390 \\
\hline Disease Activity Score With 28-Joint Counts (DAS28), median (IQR) & $3.6(3.6-4.1)$ & $3.6(3.6-5.2)$ & $3.6(3.6-4.4)$ & $0.013^{*}$ \\
\hline Simplified Disease Activity Index (SDAI), median (IQR) & $17.0(17.0-20.7)$ & $17.0(17.0-19.8)$ & $17.0(17.0-25.2)$ & 0.435 \\
\hline Clinical Disease Activity Index (CDAI), median (IQR) & $13.4(13.4-17.0)$ & $13.4(13.4-17.0)$ & $13.4(\mid 3.4-20.0)$ & 0.655 \\
\hline \multicolumn{5}{|l|}{ Disease Activity Score With 28-Joint Counts (DAS28), n (\%) } \\
\hline Remission & $12(10.3)$ & $7(58.3)$ & $5(4 I .7)$ & 0.292 \\
\hline Low & II (9.4) & $8(72.7)$ & $3(27.3)$ & \\
\hline Moderate & $82(70.1)$ & $43(52.4)$ & $39(47.6)$ & \\
\hline High & $12(10.3)$ & $4(33.3)$ & $8(66.7)$ & \\
\hline \multicolumn{5}{|l|}{ Clinical Disease Activity Index (CDAl), n (\%) } \\
\hline Remission & $3(2.6)$ & $3(100.0)$ & $0(0.0)$ & 0.225 \\
\hline Low & $22(18.8)$ & $12(54.5)$ & $10(45.5)$ & \\
\hline Moderate & $85(72.6)$ & $45(52.9)$ & $40(47.1)$ & \\
\hline High & $7(6.0)$ & $2(28.6)$ & $5(7 I .4)$ & \\
\hline \multicolumn{5}{|l|}{ Simplified Disease Activity Index (SDAI), n (\%) } \\
\hline Remission & I (0.9) & I (100.0) & $0(0.0)$ & 0.231 \\
\hline Low & $10(8.5)$ & $6(60.0)$ & $4(40.0)$ & \\
\hline Moderate & $100(85.5)$ & $54(54.0)$ & $46(46.0)$ & \\
\hline High & $6(5.1)$ & I (I6.7) & $5(83.3)$ & \\
\hline
\end{tabular}

Notes: *Significant according to a significance level of $P \leq 0.05$. Bold formatting indicates $P$ value.

Abbreviations: SD, standard deviation; IQR, interquartile range.

0.757). Finally, pain was significantly associated with higher MTX intolerance (AOR 1.018 [95\% CI: 1.003, 1.033]; $\mathrm{P}=0.020$ ). The remaining factors did not show significant associations with MTX intolerance.
Multiple linear regression was carried out to predict changes in the MISS score, while being tested against different disease activity scores, one at a time, namely: DAS28, CDAI, and SDAI, in addition to pain scores, 
Table 4 Binary Logistic Regression Analysis to Determine Factors Associated with Methotrexate Intolerance Among the Study Population Adjusted by Age, Gender, and Disease Duration

\begin{tabular}{|c|c|c|c|}
\hline Factors & Adjusted Odds Ratio & 95\% Confidence Interval & P-value \\
\hline \multicolumn{4}{|l|}{ Gender } \\
\hline \multicolumn{4}{|l|}{ Male (Ref.) } \\
\hline Female & 6.724 & {$[1.420,31.843]$} & $0.016 *$ \\
\hline Age (years) & 0.975 & {$[0.945,1.006]$} & 0.115 \\
\hline Rheumatoid arthritis duration & 1.005 & {$[0.938,1.077]$} & 0.889 \\
\hline \multicolumn{4}{|l|}{ Education } \\
\hline \multicolumn{4}{|l|}{ Lower level (Ref.) } \\
\hline Higher level & 0.819 & {$[0.312,2.150]$} & 0.685 \\
\hline \multicolumn{4}{|l|}{ Marital status } \\
\hline \multicolumn{4}{|l|}{ Unmarried (Ref.) } \\
\hline Married & 2.549 & {$[1.037,6.270]$} & $0.042 *$ \\
\hline \multicolumn{4}{|l|}{ Living } \\
\hline \multicolumn{4}{|l|}{ In Riyadh (Ref.) } \\
\hline Outside Riyadh & 0.614 & {$[0.219,1.727]$} & 0.356 \\
\hline \multicolumn{4}{|l|}{ Smoking } \\
\hline \multicolumn{4}{|l|}{ No (Ref.) } \\
\hline Yes & 0.677 & {$[0.044,10.447]$} & 0.780 \\
\hline Methotrexate dose & 1.041 & {$[0.942,1.152]$} & 0.430 \\
\hline \multicolumn{4}{|l|}{ Route of administration } \\
\hline \multicolumn{4}{|l|}{ Oral (Ref.) } \\
\hline Subcutaneous & 0.591 & {$[0.235,1.488]$} & 0.265 \\
\hline \multicolumn{4}{|l|}{ Time of administration } \\
\hline \multicolumn{4}{|l|}{ Morning (Ref.) } \\
\hline Evening & 1.191 & {$[0.500,2.838]$} & 0.693 \\
\hline \multicolumn{4}{|c|}{ Methotrexate in relation to meals } \\
\hline \multicolumn{4}{|l|}{ Before (Ref.) } \\
\hline Between & 0.835 & {$[0.103,6.787]$} & 0.866 \\
\hline After & 0.643 & {$[0.099,4.179]$} & 0.644 \\
\hline \multicolumn{4}{|l|}{ Rheumatoid factor } \\
\hline \multicolumn{4}{|l|}{ No (Ref.) } \\
\hline Yes & 0.502 & {$[0.101,2.498]$} & 0.400 \\
\hline \multicolumn{4}{|l|}{ Anti-cyclic citrullinated peptide } \\
\hline \multicolumn{4}{|l|}{ No (Ref.) } \\
\hline Yes & 1.688 & {$[0.096,29.817]$} & 0.721 \\
\hline \multicolumn{4}{|c|}{ Traditional disease-modifying antirheumatic drugs } \\
\hline \multicolumn{4}{|l|}{ No (Ref.) } \\
\hline Yes & 0.695 & {$[0.299,1.615]$} & 0.398 \\
\hline \multicolumn{4}{|l|}{ Biologics } \\
\hline \multicolumn{4}{|l|}{ No (Ref.) } \\
\hline Yes & 1.640 & {$[0.707,3.805]$} & 0.250 \\
\hline
\end{tabular}


Table 4 (Continued).

\begin{tabular}{|c|c|c|c|}
\hline Factors & Adjusted Odds Ratio & 95\% Confidence Interval & P-value \\
\hline \multicolumn{4}{|l|}{ Other medications } \\
\hline \multicolumn{4}{|l|}{ No (Ref.) } \\
\hline Yes & 0.548 & {$[0.163,1.835]$} & 0.329 \\
\hline Erythrocyte sedimentation rate & 1.003 & {$[0.980,1.026]$} & 0.819 \\
\hline C-Reactive protein & 1.002 & {$[0.995,1.009]$} & 0.512 \\
\hline \multicolumn{4}{|l|}{ Disease Activity Score With 28-Joint Counts (DAS28) } \\
\hline \multicolumn{4}{|l|}{ Remission (Ref.) } \\
\hline Low & 0.985 & {$[0.143,6.778]$} & 0.988 \\
\hline Moderate & 1.539 & {$[0.421,5.630]$} & 0.514 \\
\hline High & 2.770 & {$[0.500,15.335]$} & 0.243 \\
\hline Disease Activity Score With 28-Joint Counts (DAS28) & 1.612 & {$[1.032,2.517]$} & $0.036 *$ \\
\hline Clinical Disease Activity Index (CDAl) & 1.059 & {$[0.991,1.132]$} & 0.090 \\
\hline Simplified Disease Activity Index (SDAI) & 1.071 & {$[0.988,1.161]$} & 0.098 \\
\hline Patient global assessment (PtGA) & 1.023 & {$[1.007,1.040]$} & $0.005^{*}$ \\
\hline Provider global assessment (PrGA) & 0.998 & {$[0.983,1.013]$} & 0.757 \\
\hline Pain using 100 visual analogue scale & 1.018 & {$[1.003,1.033]$} & $0.020 *$ \\
\hline
\end{tabular}

Notes: *Significant according to a significance level of $P \leq 0.05$. Bold formatting indicates $P$ value.

PtGA, and PrGA, taking age, gender, and disease duration into consideration in each single disease activity regression model. It was found that per unit increase in pain corresponded to a 0.046 -point increase in the MISS score, at $\mathrm{P}=0.012$. In addition, per unit increase in PtGA corresponded to 0.056 point increase in the MISS score, at $\mathrm{P}=0.003$, showing that PtGA was a major influential factor in the results of DAS28, CDAI, and SDAI. The remaining factors did not show a statistical significance and are displayed in Table 5. The predominant factor that directs MTX intolerance was found to be behavioral factors as shown in the plotted radar (Figure 1).

\section{Discussion}

Despite MTX being an anchor drug for management of RA, its use is associated with GI intolerance. This necessitates recognition of factors associated with MTX intolerance as they influence a patient's quality of life and affect their adherence to MTX therapy. ${ }^{1,4}$ In this study, we determined the prevalence of MTX intolerance among Saudi patients with RA, using the MISS questionnaire, and we investigated the relationship between RA, drug-related factors, and MTX intolerance.

In our study, we found a high prevalence of MTX intolerance in RA patients in Saudi Arabia, with $47 \%$ of the participants being MTX-intolerant. The prevalence was much higher than what was reported in a similar study in the Netherlands. ${ }^{8}$

Table 5 Model of Linear Regression to Determine Factors Affecting Methotrexate Intolerance Severity Score (MISS), Adjusted to Age, Gender, and Rheumatoid Arthritis Duration

\begin{tabular}{|l|l|l|l|l|l|l|}
\hline Factors & Unstandardized B & Standard Error & Standardized Coefficients Beta & $\mathbf{t}$ & $\mathbf{C l}$ & $\mathbf{P}$-value \\
\hline CDAI & 1.657 & 0.894 & 0.172 & 1.854 & {$[-0.115,3.429]$} & $\mathbf{0 . 0 6 7}$ \\
SDAI & 1.975 & 1.212 & 0.150 & 1.630 & {$[-0.427,4.377]$} & $\mathbf{0 . 1 0 6}$ \\
DAS28 & 1.193 & 0.666 & 0.166 & 1.791 & {$[-0.128,2.514]$} & $\mathbf{0 . 0 7 6}$ \\
Pain & 0.046 & 0.018 & 0.241 & 2.545 & {$[0.010,0.082]$} & $\mathbf{0 . 0 1 2}$ \\
PtGA & 0.056 & 0.018 & 0.278 & 3.090 & {$[0.020,0.091]$} & $\mathbf{0 . 0 0 3 *}$ \\
PrGA & -0.006 & 0.020 & -0.028 & -0.277 & {$[-0.045,0.034]$} & $\mathbf{0 . 7 8 2}$ \\
\hline
\end{tabular}

Notes: ${ }^{*}$ Using 100 Visual Analogue Scale. *Significant according to a significance level of $P \leq 0.05$, bold formatting indicates $P$ value.

Abbreviations: $\mathrm{Cl}$, confidence interval; CDAl, Clinical Disease Activity Index; SDAl, Simplified Disease Activity Index; DAS28, Disease Activity Score with 28-Joint Counts; PtGA, patient global assessment; PrGA, provider global assessment. 


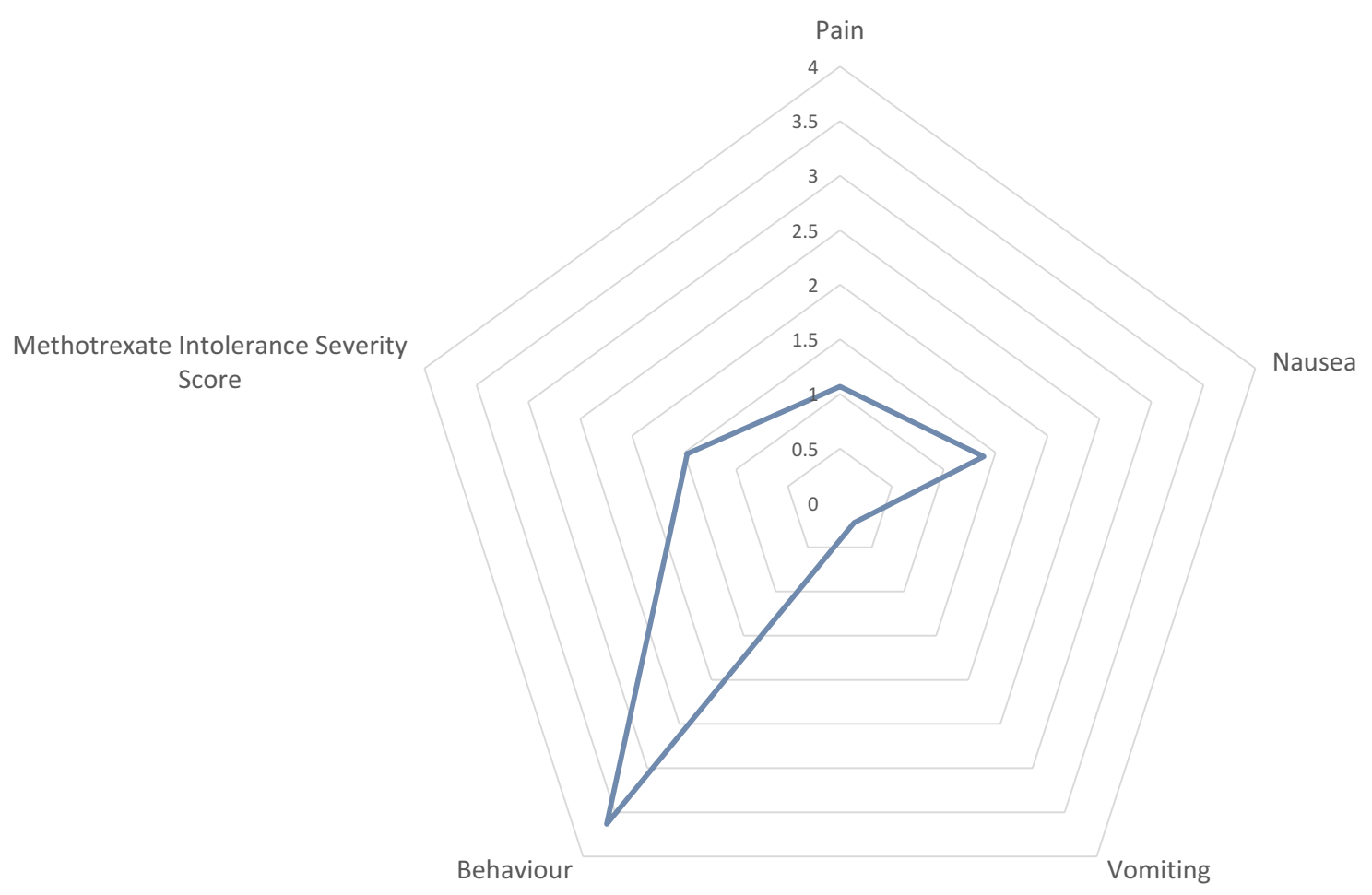

Figure I Radar chart of Methotrexate Intolerance Severity Score (MISS) and related components.

The reason behind the high prevalence of MTX intolerance in our study can be explained by our findings, which revealed that behavioral intolerance is the predominant factor that directs MTX intolerance. This is supported by the findings in Albaqami et al, as they identified a higher percentage of behavioral intolerance in the Saudi population compared with GI intolerance. ${ }^{9}$ Further explanation can be provided by how MTX is handled in the Saudi health system, where MTX is labeled as a chemotherapeutic agent which can lead to a negative psychological impact on the patients.

Ćalasan et al found that more female than male patients were intolerant ( $75 \%$ versus $25 \%$ ); however, this difference was statistically insignificant. ${ }^{8}$ Our study also revealed that the female gender was significantly associated with a higher MTX intolerance. Therefore, we may speculate that the influence of gender difference on pharmacokinetic of MTX, since MTX is mainly eliminated by renal excretion and glomerular filtration is, on average, lower in women than in men. ${ }^{14,15}$ In fact, the population kinetic analysis of long-term MTX in patients with RA revealed a gender-specific difference in its clearance even after correcting for the effects of body weight and creatinine clearance. As a result, the author suggested that females may be at increased risk of MTX toxicity; thus, it may be appropriate to use lower dosages in female patients. ${ }^{16}$ However, it is worth mentioning that the percentage of male gender in our study population was very small, therefore, results should be interpreted with caution.

Furthermore, this study has brought to our interest the association between PtGA and MTX intolerance. As demonstrated, per unit increase in PtGA significantly corresponds to an increase in the MISS score. This is to be expected since PtGA reflects on the patient's personal opinion of perceived current global status. For instance, PtGA in RA patients was strongly and positively correlated with other self-reported measures, such as pain and symptoms of depression. ${ }^{17}$ Since the MISS questionnaire also assesses behavioral symptoms such as restlessness, crying, and irritability, the association between a high MISS score and PtGA can be explained by this overlap.

Moreover, several factors have been suggested to be associated with MTX intolerance in literature, among them were young age, less comorbidities, high MTX dose, and parenteral route of administration. ${ }^{6,8,18}$ On the contrary, these factors did not show an association with MTX intolerance in our study; however, this could be due to low sample size. Furthermore, pain score using 100 visual analogue scale was significantly high in MTX-intolerant group with a significance level of $\mathrm{P}=0.010$. Additionally, using multiple linear regression, we found that per unit increase in pain significantly corresponded to a further 
increase of the MISS score. Using the binary logistic regression analysis, we also found that DAS28 was significantly associated with higher MTX intolerance. We also investigated the association between MTX intolerance and other disease-related factors; however, none of them showed a significant association with MTX intolerance. Regarding marital status, it was observed that married individuals were more likely to be MTX-intolerant. Although this was not previously reported in other literature, the fact of unmeasured confounding variables as social stress should be further investigated. Although other confounding variables may play a role, it is important to note that as a cross-sectional study, this result may be attributed to a random statistical result.

Our study was not without limitations. Our study was a cross-sectional survey with a relatively small number of participants; thus, it did not address the association between variables in detail, especially for time-varying covariates such as disease activity. MISS score was not normally distributed thus some might argue about using linear regression; however, since our sample size is greater than 50 we went with linear regression despite this limitation. Another limitation was the missing data from patient medical records; however, missing values mostly were less than $15 \%$ and we dealt with it by imputing the missing values with the mean. Future studies are needed to explore the relationship between RA related factors and MTX intolerance, in a prospective nature, using a higher sample size. The current study demonstrates the prevalence of MTX intolerance among patients with RA in the Saudi population, while exploring its relation to several factors. To the best of our knowledge, the relationship between RA related factors and MTX intolerance was not thoroughly investigated in the literature. Thus, the current paper has an advantage of being a novel study that has targeted this area and is the first study to identify a relationship between MTX intolerance and female gender, patient global assessment, and impact of patient-reported outcome on side effect profile of medications, including MTX.

\section{Conclusion}

In conclusion, MTX intolerance is common among RA patients in the Saudi population and is associated with the female gender, marriage, pain, and more active disease, based on patient global assessment and disease activity score with 28-joint counts.

\section{Data Sharing Statement}

The datasets used and/or analyzed during the current study are available from the corresponding author upon reasonable request.

\section{Ethics Approval and Informed Consent}

Institutional review board acceptance from King Saud University Medical City was obtained (Number E-172396) and included patients signed an informed consent after the investigators discussed the research with the patient.

\section{Consent for Publication}

Written informed consent was obtained from study participants.

\section{Acknowledgments}

This research project was supported by a grant from the "Research Center of the Female Scientific and Medical Colleges," Deanship of Scientific Research, King Saud University.

\section{Author Contributions}

All authors contributed extensively to the work presented in this paper, have drafted or substantially revised the article, reviewed the final manuscript, agree to take responsibility for the content of the article and have approved the manuscript and agree with its submission to Open Access Rheumatology: Research and Reviews. All authors contributed towards data analysis, drafting and critically revising the paper, gave final approval of the version to be published, and agreed to be accountable for all aspects of the work.

\section{Disclosure}

The authors report no conflicts of interest for this work.

\section{References}

1. Pincus T, Gibson KA, Castrejón I. Update on methotrexate as the anchor drug for rheumatoid arthritis. Bull Hosp Joint Dis. 2013;71 (Suppl 1):S9-S19.

2. Sokka T, Kautiainen H, Toloza S, et al. QUEST-RA: quantitative clinical assessment of patients with rheumatoid arthritis seen in standard rheumatology care in 15 countries. Ann Rheum Dis. 2007;66 (11):1491-1496. doi:10.1136/ard.2006.069252

3. Al-Niaimi F, Cox NH. Methotrexate safety: from prescribing to labelling. $B r \quad J$ Dermatol. 2009;160(6):1345-1346. doi:10.1111/ j.1365-2133.2009.09111.x 
4. Brunner HI, Johnson AL, Barron AC, et al. Gastrointestinal symptoms and their association with health-related quality of life of children with juvenile rheumatoid arthritis: validation of a gastrointestinal symptom questionnaire. J Clin Rheumatol. 2005;11(4):194-204. doi:10.1097/01.rhu.0000173616.81928.44

5. Chan ESL, Cronstein BN. Mechanisms of action of methotrexate. Bull Hosp Joint Dis. 2013;71(Suppl 1):S5-S8.

6. Fatimah N, Salim B, Nasim A, Hussain K, Gul H, Niazi S. Frequency of methotrexate intolerance in rheumatoid arthritis patients using methotrexate intolerance severity score (MISS questionnaire). Clin Rheumatol. 2016;35(5):1341-1345. doi:10.1007/s10067-016-3243-8

7. Bulatović M, Heijstek MW, Verkaaik M, et al. High prevalence of methotrexate intolerance in juvenile idiopathic arthritis: development and validation of a methotrexate intolerance severity score. Arthritis Rheum. 2011;63(7):2007-2013. doi:10.1002/art.30367

8. Ćalasan MB, van den Bosch OFC, Creemers MCW, et al. Prevalence of methotrexate intolerance in rheumatoid arthritis and psoriatic arthritis. Arthritis Res Ther. 2013;15(6):R217. doi:10.1186/ar4413

9. Albaqami J, Alshalhoub R, Almalag H, et al. Prevalence of methotrexate intolerance among patients with rheumatoid arthritis using the Arabic version of the methotrexate intolerance severity score. Int $J$ Rheum Dis. 2019;22(8):1572-1577. doi:10.1111/1756185X.13637

10. Aletaha D, Neogi T, Silman AJ, et al. 2010 Rheumatoid arthritis classification criteria: an American College of Rheumatology/ European League Against Rheumatism collaborative initiative. Arthritis Rheum. 2010;62(9):2569-2581. doi:10.1002/art.27584

11. von Elm E, Altman DG, Egger M, Pocock SJ, Gøtzsche PC, Vandenbroucke JP. The Strengthening the Reporting of Observational Studies in Epidemiology (STROBE) statement: guidelines for reporting observational studies. Bull World Health Organ. 2007;85(11):867-872. doi:10.2471/BLT.07.045120
12. Malmström V, Catrina AI, Klareskog L. The immunopathogenesis of seropositive rheumatoid arthritis: from triggering to targeting. Nat Rev Immunol. 2017;17(1):60-75. doi:10.1038/nri.2016.124

13. Anderson JK, Zimmerman L, Caplan L, Michaud K. Measures of rheumatoid arthritis disease activity: Patient (PtGA) and Provider (PrGA) Global Assessment of Disease Activity, Disease Activity Score (DAS) and Disease Activity Score With 28-Joint Counts (DAS28), Simplified Disease Activity Index (SDAI), Cl. Arthritis Care Res (Hoboken). 2011;63(S11):S14-S36. doi:10.1002/acr.20621

14. Schwartz JB. The influence of sex on pharmacokinetics. Clin Pharmacokinet. 2003;42(2):107-121. doi:10.2165/00003088200342020-00001

15. Shen DD, Azarnoff DL. Clinical pharmacokinetics of methotrexate. Clin Pharmacokinet. 1978;3(1):1-13. doi:10.2165/00003088197803010-00001

16. Godfrey C, Sweeney K, Miller K, Hamilton R, Kremer J. The population pharmacokinetics of long-term methotrexate in rheumatoid arthritis. $\mathrm{Br} J$ Clin Pharmacol. 1998;46(4):369-376. doi:10.1046/j.1365-2125.1998.t01-1-00790.x

17. Smedstad L, Kvien T, Mourn T, Vaglum P. Correlates of patients“ global assessment of arthritis impact: a 2-year study of 216 patients with RA. Scand J Rheumatol. 1997;26(4):259-265. doi:10.3109/ 03009749709105313

18. Al-Malaq HM, Al-Arfaj HF, Al-Arfaj AS. Adverse drug reactions caused by methotrexate in Saudi population. Saudi Pharm J. 2012;20 (4):301-305. doi:10.1016/j.jsps.2012.05.004
Open Access Rheumatology: Research and Reviews

\section{Publish your work in this journal}

Open Access Rheumatology Research and Reviews is an international, peer-reviewed, open access journal publishing original research, reports, editorials, reviews and commentaries on all aspects of clinical and experimental rheumatology in the clinic and laboratory including the following topics: Pathology, pathophysiology of rheumatological diseases; Investigation, treatment and management

\section{Dovepress}

of rheumatological diseases; Clinical trials and novel pharmacological approaches for the treatment of rheumatological disorders. The manuscript management system is completely online and includes a very quick and fair peer-review system, which is all easy to use. Visit http://www.dovepress.com/testimonials.php to read real quotes from published authors. 